\title{
THERMOCHEMICAL ANALYSIS OF A FLUE GAS-DRIVEN BIOMASS GASIFICATION
}

\author{
Rafał Litka*, Sylwester Kalisz \\ Silesian University of Technology in Gliwice, Institute of Power Engineering and Turbomachinery, \\ 44-100 Gliwice, ul. Konarskiego 20, Poland
}

\begin{abstract}
One of the methods of obtaining energy from renewable sources is the technology of indirect cofiring of biomass. It consists in the gasification of secondary fuel and combustion of the generated gas in the boiler together with its primary fuel. The paper presents a thermodynamic analysis of the use of the boiler flue gases as the converting medium in the process of indirect co-firing - a technology which is being developed at the Institute of Power Engineering and Turbomachinery of the Silesian University of Technology. The basis of the analysis are the data resulting from variant calculations conducted with the use of the Gaseq program. The calculations were made for various compositions of gasified fuel and the converting medium, variable fuel/oxidiser ratios and variable gasification temperatures. As a result, the equilibrium composition and the calorific value of the generated gas were obtained. The main optimisation objective adopted here was the nondimensional efficiency coefficient, which is the ratio of the chemical energy of products to the chemical energy of the process reactants.
\end{abstract}

Keywords: co-firing, gasification, biomass, chemical equilibrium

\section{INTRODUCTION}

The chemical energy of biomass is more and more often used as the source of renewable energy. Consequently, there is a high demand for biomass, as well as for effective ways of obtaining it and its conversion into other types of energy. However, due to its varied structure and chemical composition, conversion of this fuel is not easy. Biomass can be fired or co-fired directly or indirectly. It can also be transformed into other types of fuel in the processes of degassing and gasification. Both technologies have their advantages and disadvantages.

Indirect co-firing consists in the gasification of biomass and combustion of the generated gas in the boiler together with its primary fuel. The conversion of biomass into fuel gas makes it possible to avoid many technological problems which arise if the fuel is used for energy purposes in other ways. Distinctly separated combustion and gasification zones make it possible to carry out both processes using the effects of their mutual synergy. Co-firing of gas fuel with any other fuel provides a much better combustion flexibility, and makes it possible to obtain both a higher heat fraction of the co-fired fuel and a chance to use the gas derived from biomass in the reburning technology in order to reduce emissions of nitrogen oxides.

The following can be used as the converting medium in the gasification process: air, steam, flue gases, oxygen, or mixtures of these media. In the technology which is being developed in the Institute of Power Engineering and Turbomachinery (IPET), hot boiler flue gases are used for this purpose, which 
allows an effective use of the chemical energy of gasified fuel. On the other hand, the integration of the gasifying reactor with the combustion chamber allows a maximum use of the enthalpy of the ultimate gas, due to the fact that it is not cooled after it leaves the reactor (Fig. 1), which is the case in conventional gasifying reactors. An additional benefit of such integration is the fact that there is no need to manage liquid products of gasification because organic substances included in tars remain in the gas phase until they are thermally decomposed in the combustion chamber of the boiler.

The aim of the presented analysis is to find the optimum - from the thermochemical point of view process parameters for the proposed technology of flue gas-driven biomass gasification.

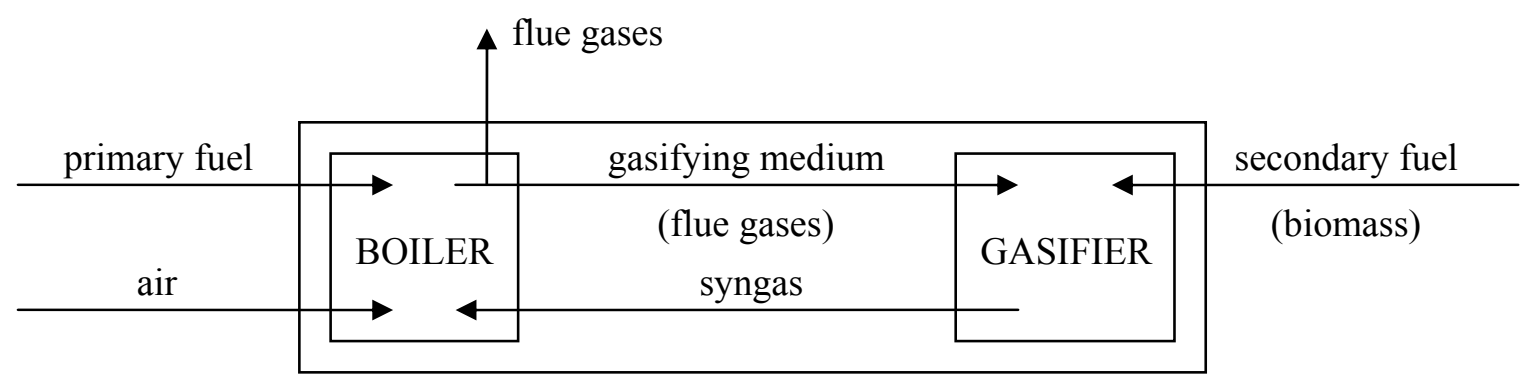

Fig. 1. Diagram of indirect co-firing system

\section{THERMOCHEMICAL ANALYSIS}

The calculations of the gasification process generally come down to a determination of the amounts of individual media and the composition of the ultimate gas for various initial input data. Equilibrium composition of the ultimate gas can be estimated with stoichiometric or non-stoichiometric methods. The stoichiometric method consists in the determination of gas composition based on a set of chemical reactions which describe the reacting system. Under given thermal conditions, reaction rate constants correspond to each reaction. On the basis of these constants and of the balances of the substances present in the reacting system, the component contents in the products are determined. The nonstoichiometric method makes use of the direct minimisation of the free enthalpy function (Gibbs function) for a given set of substances.

Gibbs function $G$ is defined by a dependence

$$
\frac{G}{R T}=\sum_{i=1}^{n S p}\left(\frac{x_{i} G_{i}^{0}}{R T}+x_{i} \ln \frac{x_{i}}{\sum x_{i}}+x_{i} \ln p\right)
$$

In the state of equilibrium, the function $G / R T$ reaches its minimum depending on the set elemental composition. In this analysis, the Gaseq program (www.gaseq.co.uk), based on the non-stoichiometric method, was used for the equilibrium calculations.

The amounts of the ultimate gas components estimated in this way diverge from experimental data; the more the state of the real system differs from the state of equilibrium, the bigger the divergence. However, the method can be used successfully at the design stage of gasification systems and during the preliminary optimisation of their basic parameters Nevertheless, it is not possible to validate the parameters of the process with the computational data before the results of the experimental analysis are known. Such experimental results allow to identify the computational model (Kozaczka, 1994; Kalina, 2011).

A non-dimensional value, which is the ratio of the chemical energy of products to the chemical energy of the process reactants, was used to compare the quality of fuel chemical conversion. The value is similar to the "cold" efficiency of the gasification process (Nadziakiewicz et al., 2007). However, the 
parameter which is determined on the basis of the equilibrium composition of the ultimate gas can reach values higher than one, which is not the case when the cold gas efficiency is determined on the basis of experimental data. It results from the fact that the efficiency obtained from equilibrium calculations does not take into account the heat energy needed for the endothermic reactions to take place. The efficiency determined in this way can only be used for comparative purposes. Therefore later in this paper, this parameter will be referred to as the chemical energy conversion rate $(C E C R)$ in order to distinguish it clearly from the cold gas efficiency.

$$
C E C R=\frac{\dot{V}_{g, d} V L H V_{g, d}}{\dot{m}_{b, d a f} L H V_{b, d a f}+V_{f g, d} V L H V_{f g, d}}
$$

\section{INPUT DATA}

In the analysis, a possibly maximum variety of the composition of reactants was taken into account, considering selected biomass fuels (Miles et al., 1995) and compositions of flue gases. The gasifying medium adopted for the analysis were the flue gases resulting from the complete combustion of two types of hard coal - flame coal and anthracite (Orłowski et al., 1979) - with two different air excess ratios of: $\lambda=1.0$ and $\lambda=1.2$. The parameters of the gasification reactants are listed in Table 1 (biomass) and Table 2 (flue gases).

Table 1. Gasified biomass characteristics

\begin{tabular}{|c|c|c|c|c|c|}
\hline & & \multicolumn{4}{|c|}{$\begin{array}{c}\text { Type of biomass } \\
\text { (nomenclature used in the paper) }\end{array}$} \\
\hline & & $\begin{array}{l}\text { Fir Mill } \\
\text { Waste } \\
\text { (B I) }\end{array}$ & $\begin{array}{c}\text { Forest } \\
\text { Residuals } \\
\text { (B II) }\end{array}$ & $\begin{array}{l}\text { Poplar- } \\
\text { Coarse } \\
\text { (B III) }\end{array}$ & $\begin{array}{l}\text { Olive Pits } \\
\text { (B IV) }\end{array}$ \\
\hline \multirow{7}{*}{$\begin{array}{l}\text { Mass fraction of main components, } \\
\% \text { (as received) }\end{array}$} & $\mathrm{C}$ & 18.95 & 25.70 & 47.39 & 49.59 \\
\hline & $\mathrm{H}$ & 2.21 & 2.35 & 5.49 & 6.28 \\
\hline & $\mathrm{O}$ & 15.66 & 20.42 & 38.32 & 35.96 \\
\hline & $\mathrm{N}$ & 0.02 & 0.53 & 0.55 & 0.42 \\
\hline & S & 0.01 & 0.06 & 0.02 & 0.05 \\
\hline & ash & 0.15 & 2.03 & 1.49 & 1.62 \\
\hline & moisture & 63.00 & 48.91 & 6.74 & 6.08 \\
\hline \multirow{3}{*}{$\begin{array}{c}\text { Molar ratio of main elements, } \\
\mathrm{kmol} / \mathrm{kmol} \\
\text { (ash-free) }\end{array}$} & $(O / C)_{b, a f}$ & $\begin{array}{c}2.84 \\
(\max )\end{array}$ & 1.87 & 0.7 & $\begin{array}{l}0.63 \\
(\mathrm{~min})\end{array}$ \\
\hline & $(H / O)_{b, a f}$ & 2.05 & $\begin{array}{c}1.94 \\
(\mathrm{~min})\end{array}$ & 2.24 & $\begin{array}{c}2.67 \\
(\max )\end{array}$ \\
\hline & $(H / C)_{b, a f}$ & $\begin{array}{c}5.82 \\
(\max )\end{array}$ & 3.63 & $\begin{array}{c}1.57 \\
(\mathrm{~min})\end{array}$ & 1.67 \\
\hline $\begin{array}{l}\text { Lower heating value, } \mathrm{MJ} / \mathrm{kg} \\
\text { (dry, ash-free) }\end{array}$ & $L H V_{b, d a f}$ & 19.19 & 19.96 & 17.93 & 20.48 \\
\hline
\end{tabular}

The fuel and the oxidiser were selected due to the content of the basic elements of the process - carbon, hydrogen and oxygen. The reactants used in the calculations were those which showed the maximum and minimum ratios of the elements (Table 1 and 2). Three variants of the molar ratio of the fuel (ash- 
free) to the oxidiser were considered: $(f / o)-2 / 1,1 / 1$ and $1 / 2$. No tar content in the products of the process was assumed.

It was also assumed that the gasification process is run at atmospheric pressure ( $p=1 \mathrm{~atm})$. The calculations were conducted for a temperature range of $200-1200^{\circ} \mathrm{C}$, determining the equilibrium composition every $25^{\circ} \mathrm{C}$.

Table 2. The gasifying medium characteristics

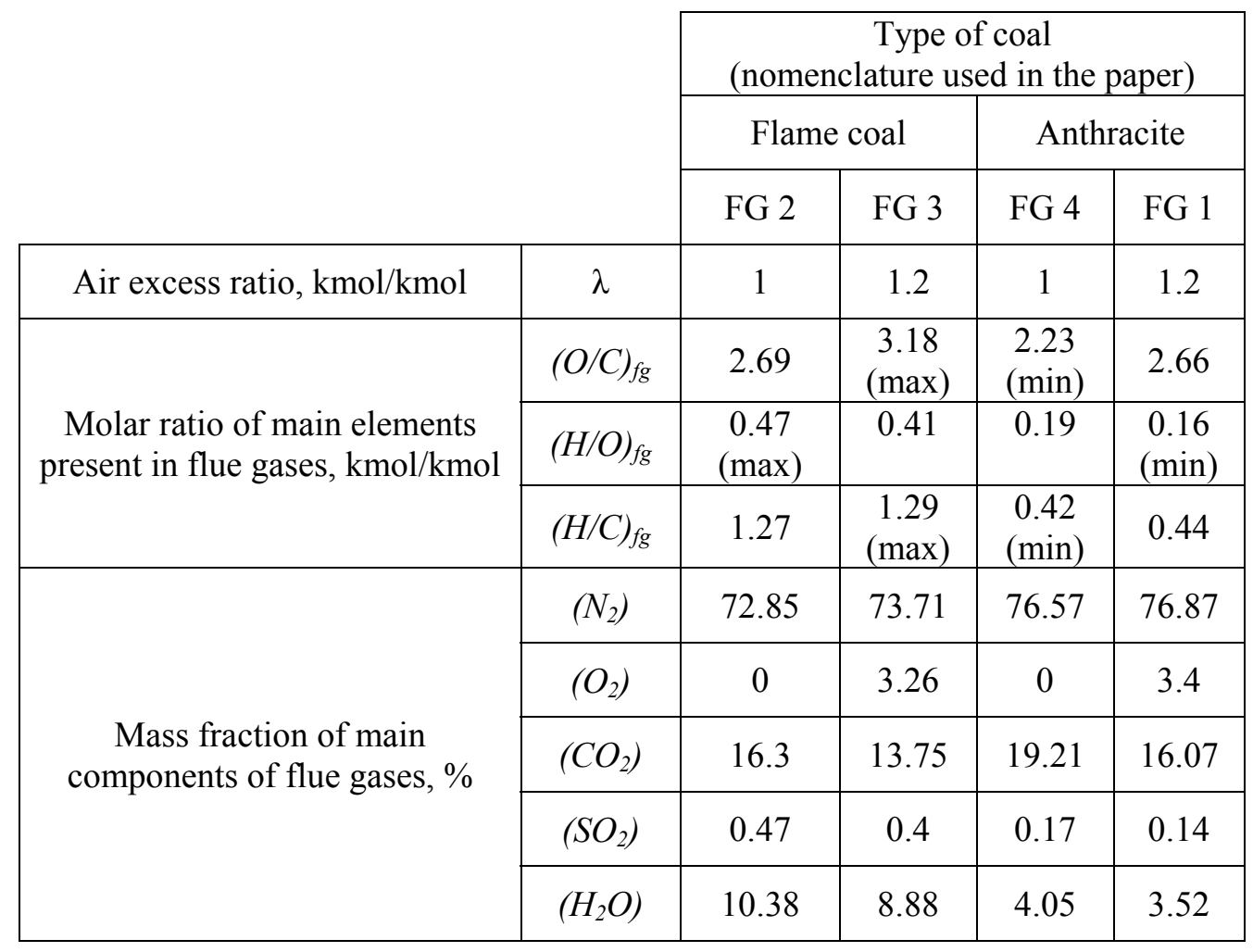

\section{ANALYSIS RESULTS}

\subsection{Temperature of total carbon conversion}

Carbon can be present in areacting system in the solid phase $C(S)$, in the gas phase (mainly in the form of oxides and hydrocarbons), or as one of the tar components. For systems in states of chemical equilibrium, with a composition allowing a total conversion of carbon element $C(S)$, there is a temperature above which the amount of carbon in the solid phase equals zero. Temperature determines the boundary for complete gasification and is of utmost importance from the technological point of view because, if known, it makes it possible to conduct the gasification process in a way that ensures the lack of combustible fractions in the solid (in this case - waste-) products of the process.

The gasification process is usually run at temperatures exceeding $800^{\circ} \mathrm{C}$ (Nadziakiewicz et al., 2007; Tomeczek, 1991). Flue gas-driven gasification of biomass which is considered as an allothermal process in which the heat carriers are hot flue gases may, however, be unable to satisfy the demand for heat for the needs of the endothermic reactions at the process temperatures of the order of $800^{\circ} \mathrm{C}$ or higher. For this reason, the presented analysis of total conversion of carbon concerns predominantly a lower range of temperatures. The analysis is also a valuable supplement to theoretical considerations of the state of chemical equilibrium and therefore more attention was given to this issue. 


\section{Regression equations}

Fig. 2 presents the temperature distribution of total conversion of carbon $t_{t c c}$ depending on the molar ratios of the basic elements of the reacting system: $O / C$ and $H / C$. For almost every fuel-oxidiser pair (except for B I - FG 3) and in the almost entire range of flo ratios included between 2/1 and 1/2 (for fuel B III and B IV the range is from $1 / 1$ to $1 / 2$ ) the distribution shows a quasi-linear dependence on the $\mathrm{O} / \mathrm{C}$ and $\mathrm{H} / \mathrm{C}$ ratio.
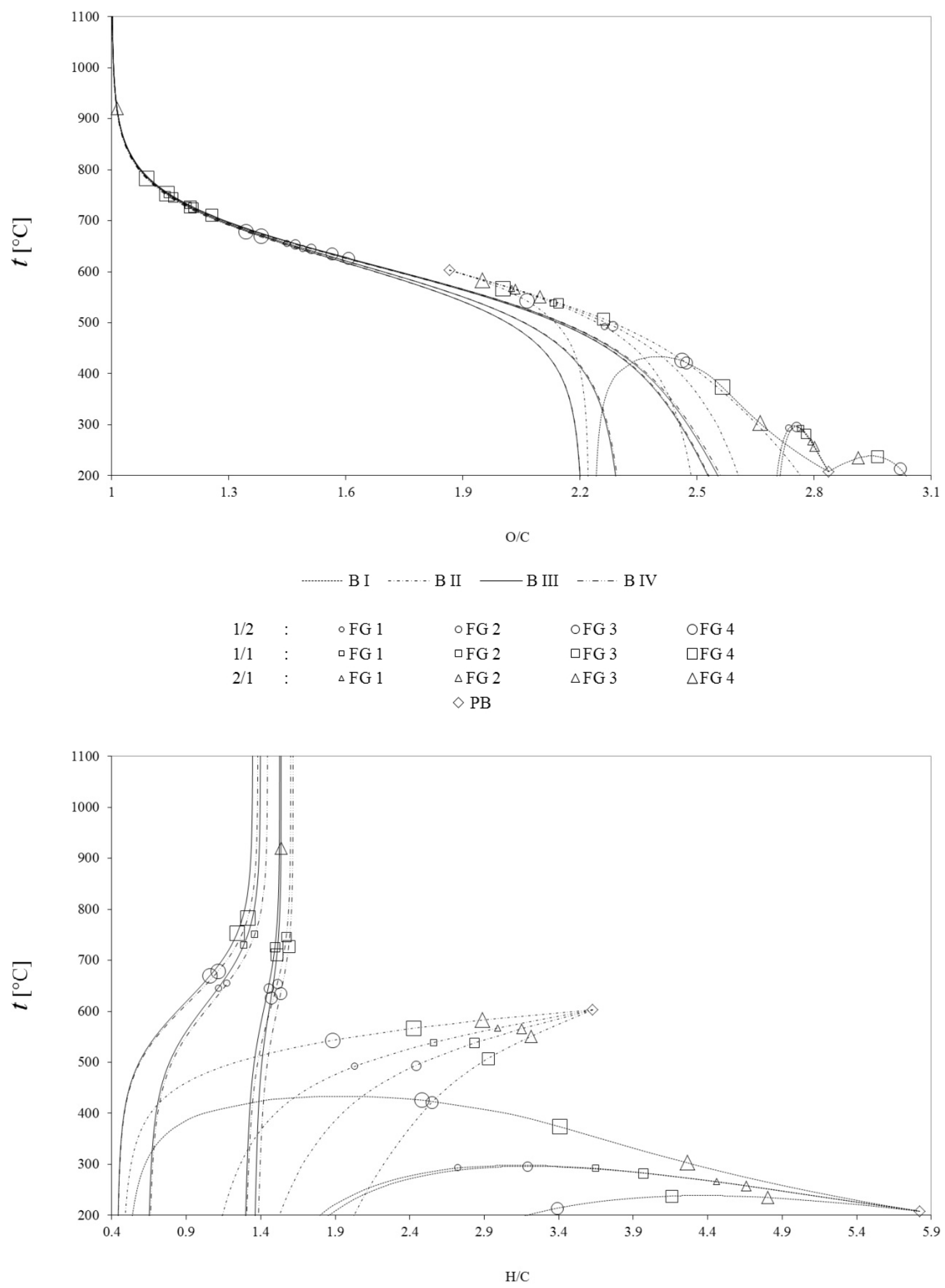

Fig. 2. Temperature distribution of total carbon conversion depending on the $O / C$ value (top) and $H / C$ value (bottom) in the reacting system 
Disregarding unlikely cases for which $O / C$ assumes values close to 1.0 , and $t_{t c c}$ tends to infinity (B III $2 / 1$ and B IV - 2/1), or the case for which $O / C$ assumes an extremely high value (B I - FG 3), multiple linear regression of the total carbon conversion temperature was carried out. The correlation coefficient was calculated as $\mathrm{R}^{2}=0.97$, together with the roots of the regression equation (3) describing the function under consideration.

$$
t_{t c c}=-16.5 O / C-236.9 H / C+1040.3\left[{ }^{\circ} \mathrm{C}\right]
$$

The Gaseq program used for the equilibrium calculations tends towards a lack of convergence in system states close to states of phase transition of its components. This type of lack of convergence can occur in a temperature range from several to a dozen-or-so degrees in the temperature of the transition environment. Therefore, in the Gaseq program it is impossible to define, in the strict sense, the exact temperature above which the content of element $C(S)$ in the system equals zero. Considering the fact that the standard error of estimate for $t_{t c c}$ is $\pm 29.1{ }^{\circ} \mathrm{C}$, it can be concluded that the accuracy of the regression equation is not too high. However, by means of Equation (3), it is possible to preliminarily estimate, in a simple way, the approximate temperature of total carbon conversion (for the adopted assumptions), knowing only the composition of the reacting system, and without conducting more complex equilibrium calculations. An extended analysis taking into account the entire range of the equilibrium composition would allow a more detailed estimation, which however is not the aim of this paper.

Series B III and B IV in Fig. 2, except for one case (FG 3), do not include data corresponding to equilibrium states at the fuel-oxidiser ratio of $2 / 1$. It results from the fact that with too little an amount of the oxidiser in the reacting system $(O / C \approx 1.0)$, the temperature of total carbon conversion increases beyond the range considered in this paper. In the analysis presented below, the cases for which the total carbon conversion is not possible at temperatures lower than $1200^{\circ} \mathrm{C}$ were omitted. The aim of that was to consider only the variants for which complete fuel gasification was possible under thermal conditions of the process similar to the real ones.

\section{Influence of the $\mathrm{O} / \mathrm{C}$ ratio}

Series for fuel B III and B IV in Fig. 2 coincide at higher temperatures. This is related to the similar composition of the two types of biomass. Almost co-linearly located fuel-oxidiser pairs marked with square and round markers of the same size (for one type of fuel) denote series for fuel B IV, if occurring at a lower $O / C$ value, and series for fuel B III, if occurring at a higher $O / C$ ratio.

Series B III - FG 3 presents the case of fuel with a very low $O / C$ ratio, gasified with flue gases with the maximum ratio of the elements. It depicts some limitations related to the use of biomass with a low $O / C$ ratio (fuels B III and B IV). This type of biomass can be completely gasified at the fuel-to-oxidiser ratio of $2 / 1$ only in cases where coal (primary fuel) has a substantial content of volatile fractions and it is burned at a high air excess ratio (FG 3), and the process temperature is higher than $920^{\circ} \mathrm{C}$. The use of flue gases with a lower $O / C$ ratio to gasify biomass of the B III or B IV type in the range of lower gasification temperatures requires that the process should be run with a higher content of the oxidiser compared to the fuel being gasified (series B III and B IV - 1/1 and 1/2).

A different situation is presented by the series for fuel B I. It is the only case where the $O / C$ ratio in the fuel is higher than that in the oxidiser (series FG 1, FG 2 and FG 4). This produces a different direction of changes in the $O / C$ ratio in the reacting system if the fuel-to-oxidiser ratio is changed from the one in other series. In these three cases, an increase in the fuel content compared to that of the oxidiser results in an increase in the $O / C$ ratio in the fuel-oxidiser system. This means that fuel B I can be gasified at such amounts of the oxidiser which are necessary for the process due to technological reasons only (e.g. transport of ultimate gas) because it contains enough oxygen for self-gasification (the thermal aspect ignored). Series B I - FG 3 for this fuel shows the maximum $O / C$ ratio in the reacting system. The extremely high value of the $O / C$ ratio for this series (from 2.91 for $f / o=2 / 1$ to 3.02 for $f / o=1 / 2$ ) results 
in the lowest maximum (equilibrium) temperature of total carbon conversion of $238^{\circ} \mathrm{C}$ for the cases under consideration.

Series B I and B II for fuels with high and medium values of the $O / C$ ratio start at the point which denotes a total lack of oxidiser in the system (i.e. pure biomass - PB). These series differ, however, in the form and the course of the curves which represent them. The series for fuels with a high $O / C$ ratio (B I) have a relative extremum, whereas the series for fuels with a medium $O / C$ ratio (B II) - an absolute extremum at point PB. Due to that, in the case of fuels with a high $O / C$ ratio, a reduction in the fuel-to-oxidiser ratio can result in both an increase and a decrease in temperature $t_{t c c}$. For other fuels, a rise in the amount of the oxidiser compared to the fuel being gasified always leads to a fall in temperature $t_{t c c}$, and the functions have one (series B II) or two (series B III and B IV) characteristic points (convexities or convexities and concavities) in the area where changes in temperature $t_{t c c}$ occur violently. With the $O / C$ ratio tending to $1.0, t_{t c c}$ tends to infinity. This means that complete gasification is possible only if $O / C \geq 1.0$ (Tomeczek, 1991).

From the technological point of view, running the gasification process at parameters close to the course of the $t_{t c c}$ function at higher values of the $O / C$ ratio in the reacting system is not beneficial because in the case of fluctuations in the process temperature, in the chemical composition of the reactants, or in the mass flow of reactants, there is a high risk of transition from the area of complete to non-complete gasification. The problem will be discussed on the most obvious example. Biomass B I is gasified at $f / o$ $=1 / 2$ with flue gases FG 3 at a temperature slightly higher than $214^{\circ} \mathrm{C}$ (series B I $-1 / 2-\mathrm{FG} 3$ ). A reduction in the air excess ratio $\lambda$ from 1.2 to 1.0 will cause a transition into the area of non-complete gasification (series B I $-1 / 2-\mathrm{FG} 2$ ), which requires a rise in the process temperature by at least $82^{\circ} \mathrm{C}$. A change in the flo value from $1 / 2$ to $1 / 1$ also will cause a transition into the area of non-complete gasification (series B I - 1/1 - FG 3), which requires a rise in the process temperature by at least $24^{\circ} \mathrm{C}$. In turn, a change of fuel from biomass B I to B IV (series B IV - 1/2 - FG 3) will require a rise in the process temperature by at least $421^{\circ} \mathrm{C}$ in order to ensure total carbon conversion.

The chart of the dependence of $t_{t c c}$ on the $O / C$ ratio (Fig. 2) shows a clear impact of changes in the process parameters on the possibility of complete gasification of biomass. For the considered variants, a change in value $\lambda$ can cause a shift of temperature $t_{t c c}$ by $133^{\circ} \mathrm{C}$ maximum, a change in $f / o$ - by maximum $293^{\circ} \mathrm{C}$, and a change in the $O / C$ ratio - even by $685^{\circ} \mathrm{C}$ (assuming that the remaining two of the three parameters remain constant). Changes in the $f / o$ and $\lambda$ values can be contained in safe limits because boilers usually operate at constant and adjustable $\lambda$, and the amount of the oxidiser fed for gasification can easily be adjusted on the basis of the set mass flow of the biomass being gasified. On the other hand, a change in the $O / C$ ratio in gasified fuel, which will result from a change in the type of biomass, could cause problems with running the process with optimum efficiency, and satisfying the condition of total carbon conversion. The more frequent are sudden changes of biomass composition caused by shortages of fuel supplu, the more serious difficulties related to that might be.

\section{Influence of the $\mathrm{O} / \mathrm{C}$ ratio}

The same conclusions can be drawn after the analysis of the course of $t_{t c c}$ depending on the $H / C$ ratio (Fig. 2). Depending on the type of fuel, the impact of the $H / C$ ratio on $t_{t c c}$, which could be defined by the slope of the curves, may be strong (series B III and B IV), significant (series B I - FG 4 and series B II), or insignificant (series B I - FG 1, FG 2, FG 3). The function also has a linear character for the fuel-oxidiser pairs, assuming constraints on the linearity range similar to those for the $\mathrm{O} / \mathrm{C}$ ratio.

\subsection{Contents of the ultimate gas main components}

In the next part of the paper, the used gasifying medium is not marked in the charts (in order to increase their clarity). The impact of the composition of the flue gases on the quality of the ultimate gas is 
presented in a descriptive form only. In Figs. 3-4 and 6-8, the ranges of the series of data relate to the whole range of the analysed compositions of flue gases - the line of each series defines the minimum and maximum values of parameters for a given fuel in the system with each of the four types of flue gases under consideration. The lower the fuel-oxidiser ratio, the bigger the ranges in the presented charts are, because at a lower $f / o$ ratio the oxidiser composition has a greater impact on the minimum and maximum values in the series.

The next charts do not take account of part of the series of the data for which coal was in the condensed phase. The reason for that was to take account of equilibrium compositions which occur at complete gasification only. Therefore, most of the series in Figs. 3-4 and 6-8 start with a line joining the beginnings of curves which define the equilibrium compositions for the complete gasification of one biomass fuel at a constant molar $f / o$ ratio, using flue gases with four different compositions. Only series B III - 2/1 relates to one composition of flue gases because only flue gases FG 3 allowed complete gasification for these conditions.

\section{Gasification reactions}

Table 3 presents aclassification of the total chemical reactions in the fuel-oxidiser system containing carbon $\mathrm{C}$, hydrogen $\mathrm{H}$, oxygen $\mathrm{O}$, nitrogen $\mathrm{N}$ and sulphur $\mathrm{S}$, depending on the temperature of the reacting system. The classification is based on the content of products in the equilibrium mixture. In order to illustrate the thermal impact of the system state on its molar mass, the ratio of the molar mass of reactants to the molar mass of products was given under the arrows indicating the reaction direction. Table 3 is a supplement to Figs. 3-5, which present the equilibrium composition of the analysed variants of biomass gasification.

Table 3. Hierarchical classification of total gasification reactions depending on the thermal state of the reacting system

\begin{tabular}{|c|c|c|c|}
\hline $\begin{array}{l}\text { Thermal state } \\
\text { of the system }\end{array}$ & The first range & The second range & The third range \\
\hline Primary reactions & $\begin{array}{c}2 \mathrm{H}_{2}+\mathrm{O}_{2} \underset{2: 3}{\rightarrow} 2 \mathrm{H}_{2} \mathrm{O} \\
\mathrm{C}+\mathrm{O}_{2} \underset{1: 2}{\rightarrow} \mathrm{CO}_{2} \\
\mathrm{C}+2 \mathrm{H}_{2} \underset{1: 3}{\rightarrow} \mathrm{CH}_{4}\end{array}$ & $\begin{array}{c}\mathrm{C}+\mathrm{H}_{2} \mathrm{O} \underset{1: 1}{\rightarrow} \mathrm{CO}+\mathrm{H}_{2} \\
\mathrm{CH}_{4}+\mathrm{H}_{2} \mathrm{O} \underset{2: 1}{\rightarrow} \mathrm{CO}+3 \mathrm{H}_{2} \\
\mathrm{CH}_{4}+\mathrm{CO}_{2} \underset{2: 1}{\rightarrow} 2 \mathrm{CO}+2 \mathrm{H}_{2}\end{array}$ & $\begin{array}{c}\mathrm{C}+\mathrm{CO}_{2} \underset{1: 1}{\rightarrow} 2 \mathrm{CO} \\
\mathrm{H}_{2}+\mathrm{CO}_{2} \underset{1: 1}{\rightarrow} \mathrm{CO}+\mathrm{H}_{2} \mathrm{O}\end{array}$ \\
\hline Secondary reactions & $\mathrm{S}+\mathrm{H}_{2} \underset{1: 2}{\rightarrow} \mathrm{H}_{2} \mathrm{~S}$ & & $\mathrm{H}_{2} \mathrm{~S}+\mathrm{CO}_{2} \underset{1: 1}{\rightarrow} \mathrm{COS}+\mathrm{H}_{2} \mathrm{O}$ \\
\hline
\end{tabular}

In lower temperatures, the dominating reactions in the system are the exothermic reactions of hydrogen with carbon and sulphur, and the carbon and hydrogen combustion reactions producing $\mathrm{CO}_{2}$ and $\mathrm{H}_{2} \mathrm{O}$ (the first range). Hydrogen combines with sulphur to form $\mathrm{H}_{2} \mathrm{~S}$, and its remaining quantity is separated to react with carbon and oxygen. The rest of oxygen combines with carbon to form $\mathrm{CO}_{2}$.

According to a rise in temperature, in the system there is less and less $\mathrm{CH}_{4}, \mathrm{CO}_{2}$ and $\mathrm{H}_{2} \mathrm{O}$, and more and more $\mathrm{CO}$ and $\mathrm{H}_{2}$ (the second range). In higher temperatures the reactions of carbon and hydrogen with $\mathrm{CO}_{2}$ (the third range) dominate, and as a result - there is more $\mathrm{CO}$ and $\mathrm{H}_{2} \mathrm{O}$ in the reacting system.

A rise in temperature also supports the reaction of $\mathrm{CO}_{2}$ with $\mathrm{H}_{2} \mathrm{~S}$ (the third range). $\mathrm{COS}$ arises then, but its content assumes insignificant values. These values, however, are by an order of values higher than the contents of the remaining compounds which result from the tertiary reactions occurring in the system. 


\section{Contents of basic combustible gases: $\mathrm{CO}, \mathrm{H}_{2}$ and $\mathrm{CH}_{4}$}

The content of $\mathrm{CO}$ in the ultimate gas increases monotonically with the rise in the process temperature (Fig. 3). The maximum value obtained for the adopted assumptions is $40.7 \%$ (series B III $-2 / 1$, flue gases FG 3). The curves of $\mathrm{H}_{2}$ content for biomass with a high and medium $H / C$ ratio have an extremum (Fig. 3) whose values are between $9.1 \%$ (series B I - 1/2, flue gases FG 1) and $28.7 \%$ (series B II - 2/1, flue gases FG 2). The maximum content of $\mathrm{H}_{2}$ is $30.9 \%$ (series B III - 2/1, flue gases FG 3). In the range of complete gasification, the amount of methane in the reacting system decreases with an increase in the process temperature (Fig. 4), and its maximum content is $9.8 \%$ (series B I - 2/1, flue gases FG 2).
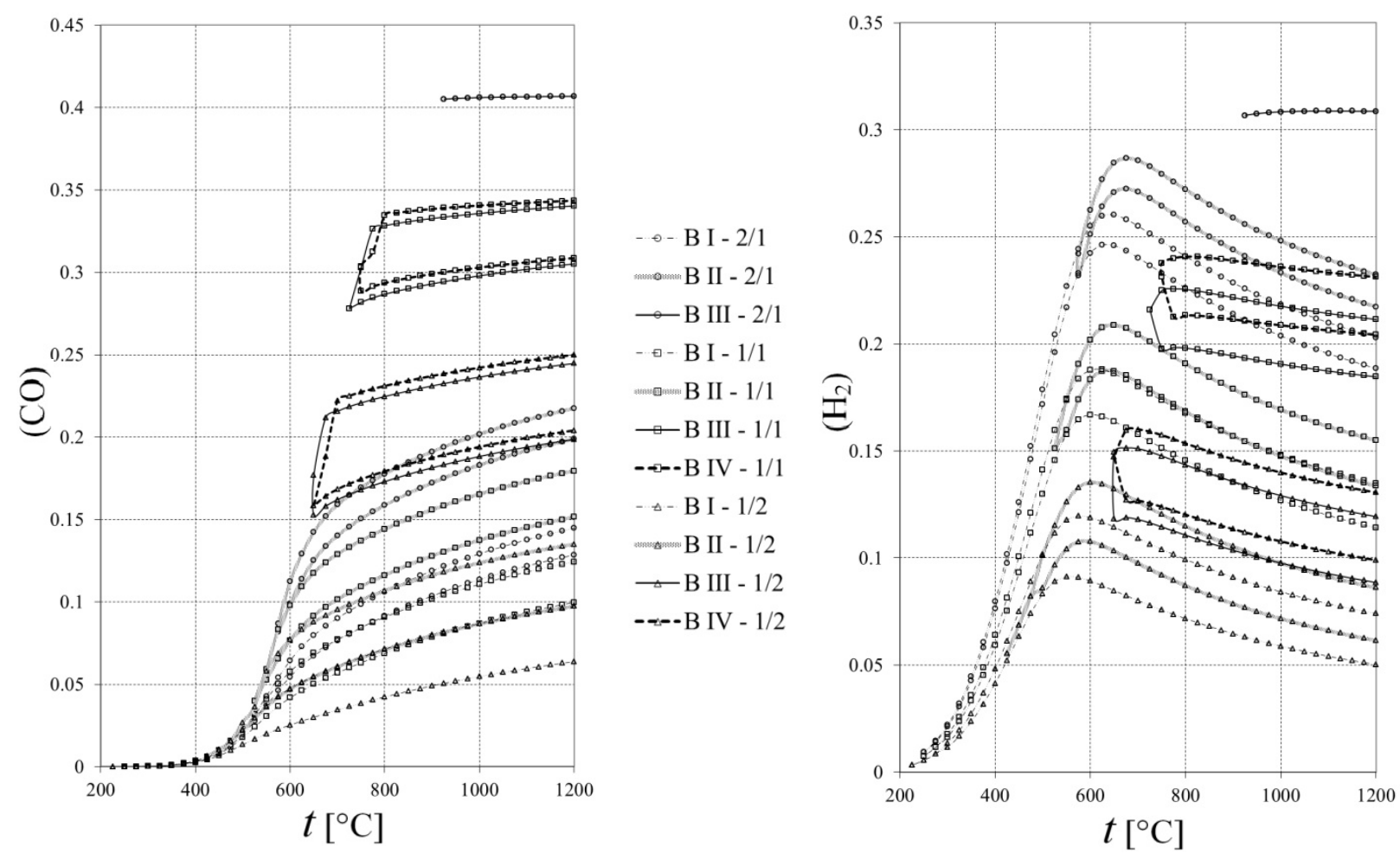

Fig. 3. Dependence of the content of $\mathrm{CO}$ (on the left) and $\mathrm{H}_{2}$ (on the right) in the ultimate gas on the gasification process temperature

The biggest gradient of $\mathrm{CO}$ content can be seen in the range of temperatures of $500-650^{\circ} \mathrm{C}$, and in the case of $\mathrm{H}_{2}$ - in the range of $300-650^{\circ} \mathrm{C}$ (Fig. 3, series B I and B II). The upper boundary of these ranges indicates the desired - due to the maximum content of $\mathrm{CO} \mathrm{i} \mathrm{H}_{2}-$ minimum temperature of the gasification process for biomass with a high and medium $O / C$ and $H / C$ ratio. It also determines the temperature above which the content of $\mathrm{CH}_{4}$ in the ultimate gas (Fig. 4) becomes negligibly small (below $1 \%$ for all variants). In the case of biomass with a low $O / C$ and $H / C$ ratio (B III and B IV), the minimum gasification temperature depends on the temperature of total carbon conversion $t_{t c c}$ and for the cases under consideration it is found between $650^{\circ} \mathrm{C}$ (series B III $-1 / 2$, flue gases FG 1, FG 2, FG 3 , and series B IV $-1 / 2$, flue gases FG 3) and $925^{\circ} \mathrm{C}$ (series B III - 2/1, flue gases FG 4).

\section{Contents of basic incombustible gases: $\mathrm{N}_{2}, \mathrm{CO}_{2}$ and $\mathrm{H}_{2} \mathrm{O}$. The molar mass of the ultimate gas}

Apart from fuel gases, the main gasification products are also: carbon dioxide, nitrogen and water vapour (steam). Figs. 4 and Fig. 6 present the contents of these compounds in the equilibrium mixture.

The maximum content of nitrogen (Fig. 4) is $57.0 \%$ (series B I - 1/2, flue gases FG 1), and the minimum one $-25.6 \%$ (series B I - 2/1, flue gases FG 2). Both these extrema are strictly related to the 
flo value, i.e. to the content of the oxidiser in reactants, because the molar content of $\mathrm{N}_{2}$ in biomass is many times higher than that in flue gases, and it is found (ash-free) between $0.01 \%$ for biomass B I and $0.28 \%$ for biomass B II (cf. Table 1 and Table 2). In the case of systems with fuel with a high or medium $\mathrm{O} / \mathrm{C}$ and $\mathrm{H} / \mathrm{C}$ ratio, the content of nitrogen decreases to a certain moment with a rise in temperature. Because $\mathrm{N}_{2}$ does not participate in any reaction which is essential for the process, its variable content is related almost exclusively to the change in the molar mass of the ultimate gas.
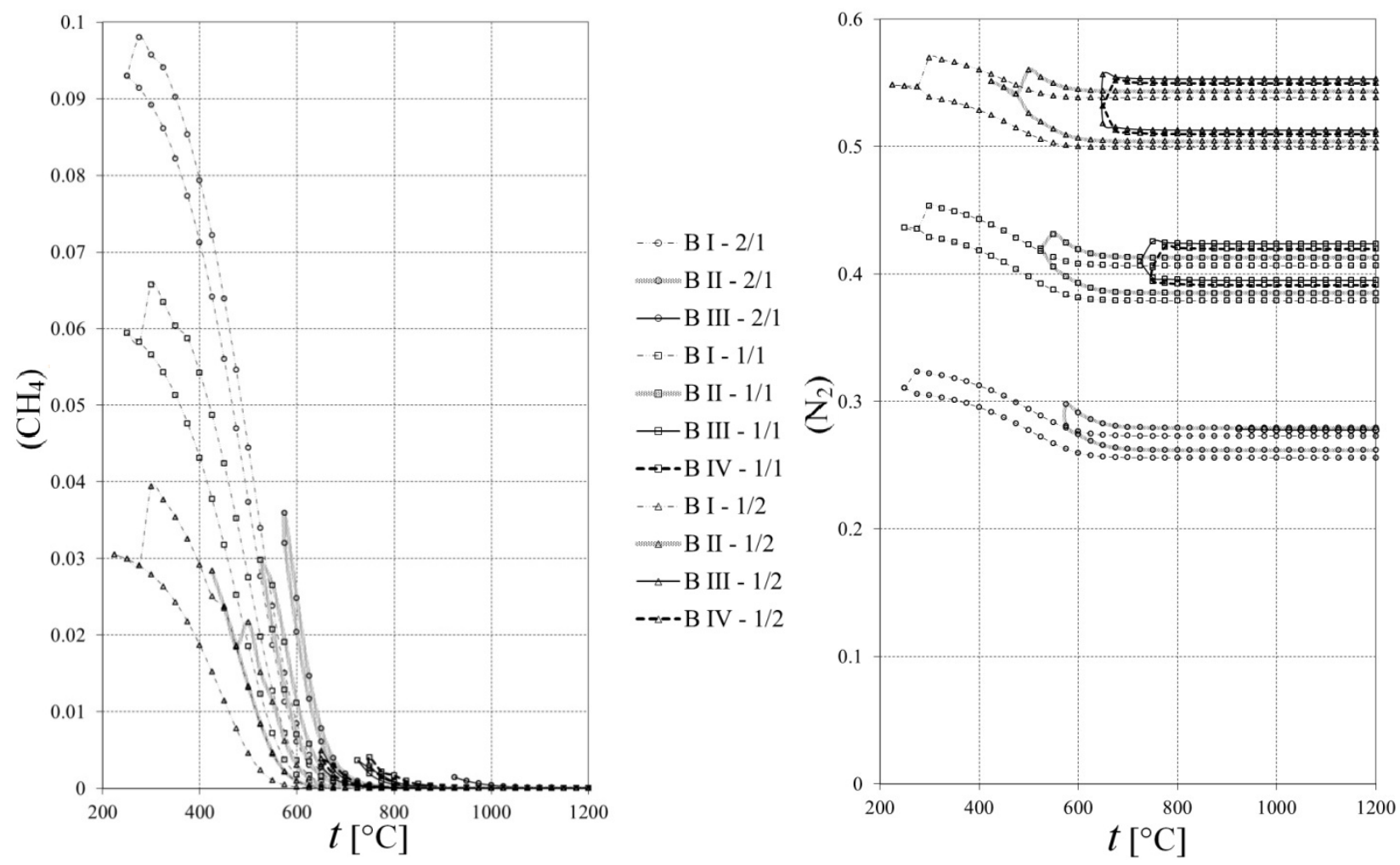

Fig. 4. Dependence of the content of CH4 (on the left) and N2 (on the right) in the ultimate gas on the gasification process temperature

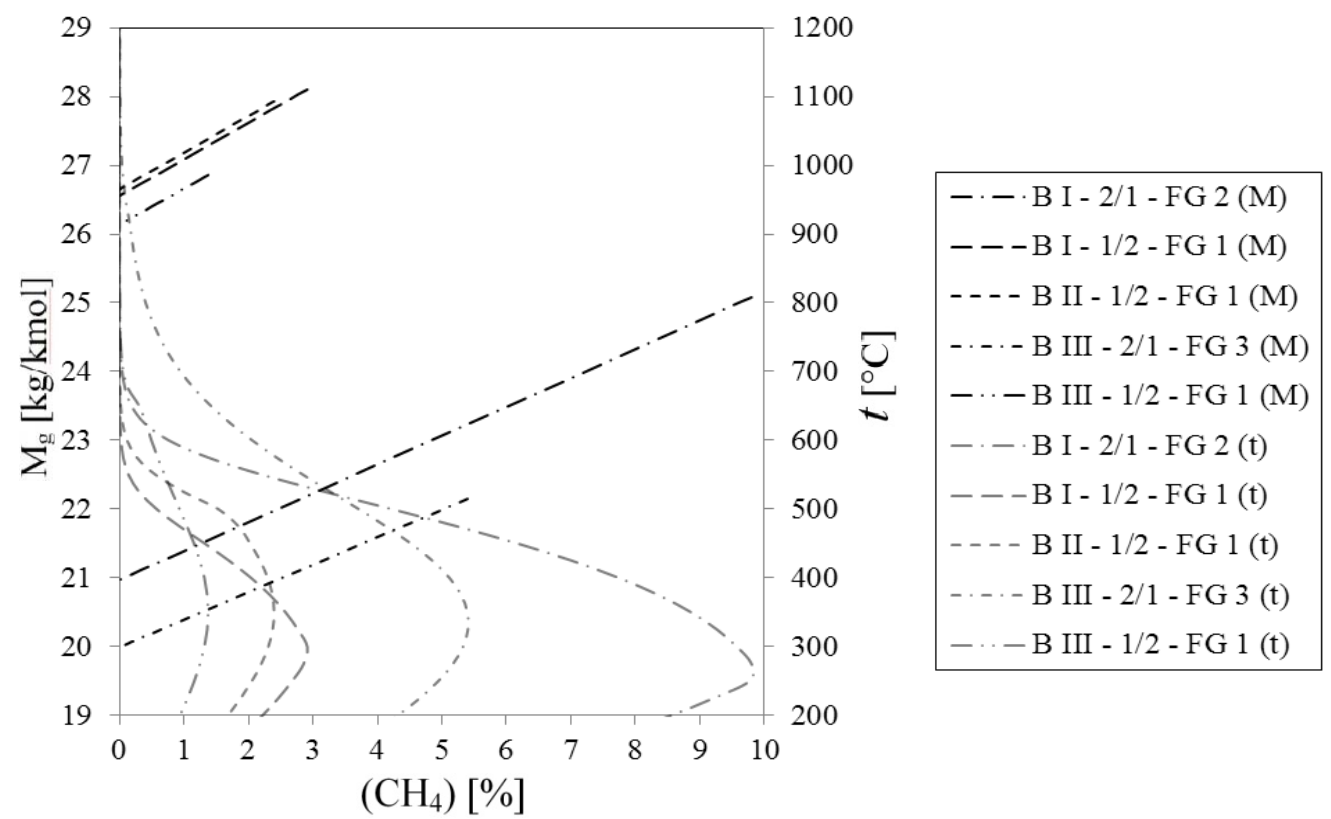

Fig. 5. The dependence of the molar mass of the ultimate gas on the $\mathrm{CH}_{4}$ content, and the dependence of the $\mathrm{CH}_{4}$ content on the equilibrium temperature 
The molar mass of the reacting system changes with temperature according to reactions presented in Table 3. For the cases under consideration, the change is caused mainly by the reactions of methane with $\mathrm{CO}_{2}$ and $\mathrm{H}_{2} \mathrm{O}$. As it occurs, the molar mass of the reaction products is reduced by half compared to the molar mass of the reactants. The dependence of the molar mass of the ultimate gas on the content of $\mathrm{CH}_{4}$ is presented in Fig. 5. The series with the semi-transparent line relate to the dependence of the $\mathrm{CH}_{4}$ content on temperature (right vertical axis), whereas the series with the same marking style, but with a non-transparent line, relate to the dependence of the molar mass of the gas on the $\mathrm{CH}_{4}$ content (left vertical axis).

The molar mass of the ultimate gas depends linearly on the content of $\mathrm{CH}_{4}$ in it. If methane is a product in the reacting system, the molar mass increases linearly with a rise in its content, and if methane is a reactant, the molar mass decreases with a fall in its content. In the temperature at which the content of $\mathrm{CH}_{4}$ is the greatest for a given composition, the molar mass of the gas also assumes the highest value. A lower methane content at the higher temperatures has a smaller influence on the change in the molar mass of gas (according to Table 3).
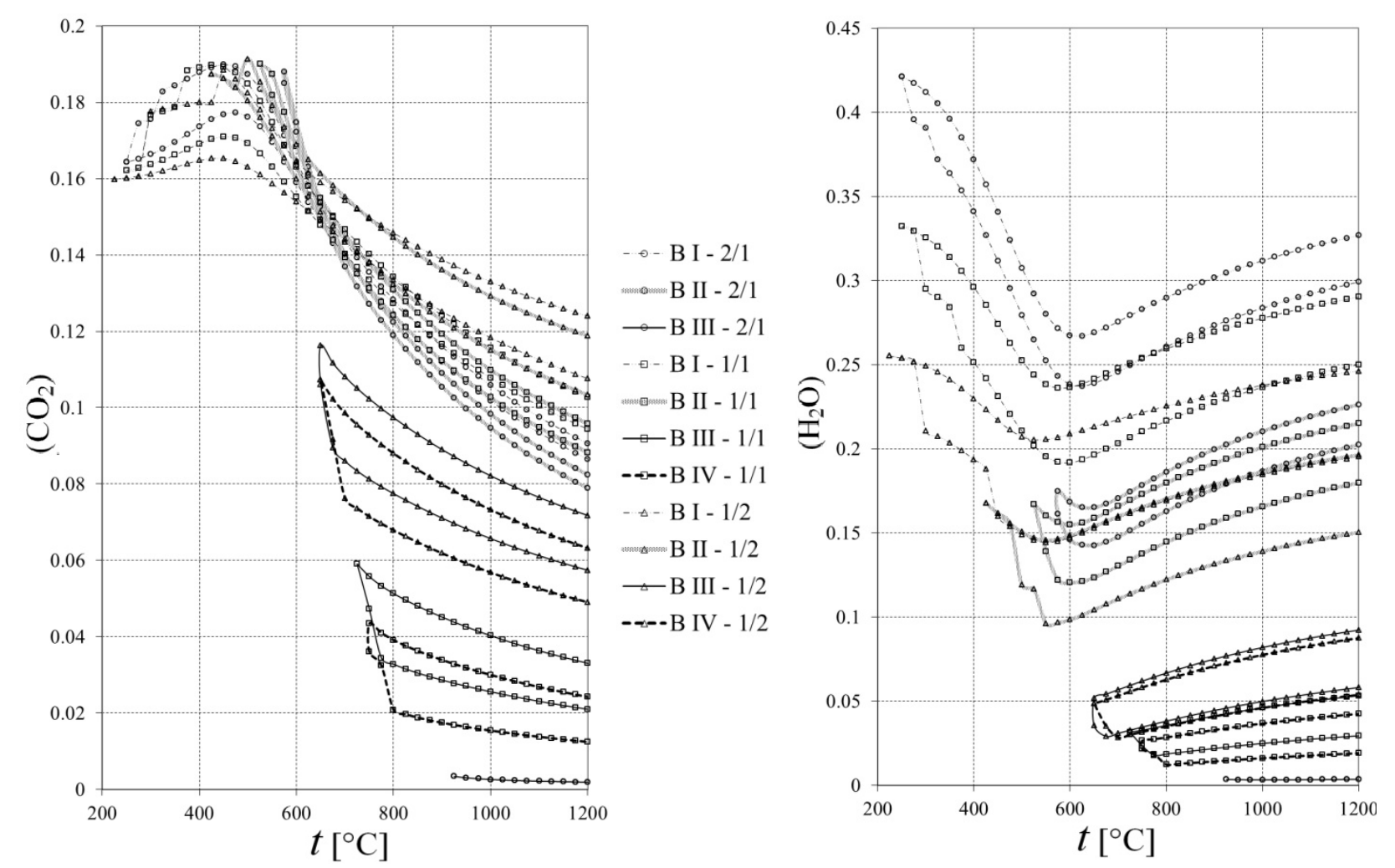

Fig. 6. Dependence of the content of $\mathrm{CO}_{2}$ (on the left) and $\mathrm{H}_{2} \mathrm{O}$ (on the right) in the ultimate gas on the gasification process temperature

The selection of series for Fig. 5 was based on the following criteria:

- the maximum and minimum molar mass of the gas after $\mathrm{CH}_{4}$ is almost completely reacted (series B II $-1 / 2-$ FG 1 and B III $-2 / 1-$ FG 3$), M_{g}=26.65 \mathrm{~kg} / \mathrm{kmol},\left(\mathrm{CH}_{4}\right) \leq 42 \mathrm{ppm}, t \geq 700^{\circ} \mathrm{C}$ and $M_{g}=19.99 \mathrm{~kg} / \mathrm{kmol},\left(\mathrm{CH}_{4}\right) \leq 40 \mathrm{ppm}, t \geq 1150^{\circ} \mathrm{C}$, respectively,

- the absolute maximum and minimum molar mass (series B I - 1/2 - FG 1 and B III - 2/1 - FG 3), $M_{g}=28.10 \mathrm{~kg} / \mathrm{kmol},\left(\mathrm{CH}_{4}\right)=2.9 \%, t=300^{\circ} \mathrm{C}$ and $M_{g}=19.99 \mathrm{~kg} / \mathrm{kmol},\left(\mathrm{CH}_{4}\right) \leq 40 \mathrm{ppm}, t \geq$ $1150^{\circ} \mathrm{C}$, respectively,

- the maximum and minimum value of the $\mathrm{CH}_{4}$ extremum (series B I - 2/1 - FG 2 and B III - 1/2 - FG 1), $M_{g}=25.08 \mathrm{~kg} / \mathrm{kmol},\left(\mathrm{CH}_{4}\right)=9.8 \%, t=275^{\circ} \mathrm{C}$ and $M_{g}=26.86 \mathrm{~kg} / \mathrm{kmol},\left(\mathrm{CH}_{4}\right)=1.4 \%, t$ $=350^{\circ} \mathrm{C}$, respectively. 
For the cases under analysis, the $\mathrm{CO}_{2}$ content increases with a rise in temperature, but only to temperatures of the order of $425-475^{\circ} \mathrm{C}$, and only for biomass B I (Fig. 6). The other three fuels (with a medium and low $\mathrm{O} / \mathrm{C}$ and $\mathrm{H} / \mathrm{C}$ ratio) are characterised by a monotonic fall in the content of $\mathrm{CO}_{2}$ with a rise in temperature. The greatest gradient of the $\mathrm{CO}_{2}$ content related to an increase in temperature coincides with the area of non-complete gasification and temperatures lower than $t_{t c c}$. High $\mathrm{O} / \mathrm{C}$ and $H / C$ ratios in the reacting system move temperature $t_{t c c}$ below the extremum of the $\mathrm{CO}_{2}$ content, and this is the reason for the unique situation of the initial increase in the content of $\mathrm{CO}_{2}$ with temperature, which is observed for fuel B I. The maximum content of $\mathrm{CO}_{2}$ is $19.1 \%$ (series B II - 1/2, flue gases FG 1 ), and the minimum one $-0.2 \%$ (series B III $-2 / 1$, flue gases FG 3 ).

Similar to $\mathrm{H}_{2}$, the $\mathrm{H}_{2} \mathrm{O}$ content (Fig. 6) also has an extremum for fuels B I and B II: minimum $-\left(\mathrm{H}_{2} \mathrm{O}\right)$ $=9.6 \%$ (series $\mathrm{B} \mathrm{II}-1 / 2$, flue gases $\mathrm{FG} 4$ ) and maximum $-\left(\mathrm{H}_{2} \mathrm{O}\right)=26.7 \%$ (series B I $-2 / 1$, flue gases FG 3). The $\mathrm{H}_{2}$ and $\mathrm{H}_{2} \mathrm{O}$ extremum is related to the change of roles that the two compounds play in the reacting system - in temperatures below the extremum the product is $\mathrm{H}_{2}$, and $\mathrm{H}_{2} \mathrm{O}$ is the reactant, whereas in temperatures above the extremum, the opposite is the case. (Fig. 3, Fig. 5, Table 3). The maximum and the minimum content of $\mathrm{H}_{2} \mathrm{O}$ for the cases under consideration is: $42.1 \%$ (series B I - 2/1, flue gases FG 3) and $0.3 \%$ (series B III - 2/1, flue gases FG 3), respectively.

\section{Contents of other components - sulphur compounds}

The analysis also took account of compounds such as $\mathrm{H}_{2} \mathrm{~S}, \mathrm{COS}, \mathrm{SO}_{2}, \mathrm{O}_{2}, \mathrm{~S}_{2}$ and $\mathrm{CS}_{2}$. Because the contents of $\mathrm{SO}_{2}, \mathrm{O}_{2}, \mathrm{~S}_{2}$ and $\mathrm{CS}_{2}$ for almost all the cases under consideration assume values below 1 ppm, their impact on the process was ignored.

Because $\mathrm{H}_{2} \mathrm{~S}$ is predominant among sulphur compounds in products, its content depends mainly on the content of sulphur in the reacting system. The highest content of $\mathrm{H}_{2} \mathrm{~S}$ in the wet ultimate gas occurs at a temperature close to $t_{t c c}$ and $f / o=1 / 2$. For biomass B I it amounts to $3484 \mathrm{ppm}$, for B II $-3452 \mathrm{ppm}$, for B IV - $3241 \mathrm{ppm}$, and for B III - $3236 \mathrm{ppm}$. All these extrema occur if gasification is conducted with flue gases FG 2, due to their maximum content of $\mathrm{SO}_{2}$. The lowest content of $\mathrm{H}_{2} \mathrm{~S}$ was observed for the maximum temperature considered in the analysis $\left(1200^{\circ} \mathrm{C}\right)$ and $f / o=2 / 1$. For biomass B II it amounts to $691 \mathrm{ppm}$, and for B I- $522 \mathrm{ppm}$. The minima correspond to cases where the oxidiser were flue gases FG 1 with the lowest content of $\mathrm{SO}_{2}$. Because for the adopted assumptions at $f / o=2 / 1$ flue gases FG 1 do not give real results with biomass with a low $O / C$ and $H / C$ ratio, these fuels reach minimum contents of $\mathrm{H}_{2} \mathrm{~S}$ also for flue gases FG 1 , but at $f / o=1 / 1$. For biomass B IV the content value is 828 ppm, and for B III - 777 ppm.

If temperature rises, the $\mathrm{H}_{2} \mathrm{~S}$ content decreases, and the COS content increases in a monotonic way (according to Table 3). The maximum content of COS in the ultimate gas (187 ppm) occurs for biomass B III, $f / o=1 / 2$, flue gases FG 2 and the temperature of $1200^{\circ} \mathrm{C}$.

Comparing the contents of $\mathrm{H}_{2} \mathrm{~S}$ and $\mathrm{COS}$ with the composition of the types of biomass (Table 1) and the composition of the flue gases (Table 2), it can be seen that the content of sulphur compounds in the ultimate gas depends mainly on the content of sulphur in the gasifying medium. This is related to a much higher content of sulphur in flue gases (in the burned coal) than in biomass.

\subsection{Ultimate gas lower calorific value}

The lower calorific value of the ultimate gas (Fig. 7) ranges from $1.516 \mathrm{MJ} / \mathrm{Nm}^{3}$ (biomass B I, series 1/2, flue gases FG 1) for a fuel with a high $O / C$ and $H / C$ ratio (low C content) to $8.540 \mathrm{MJ} / \mathrm{Nm}^{3}$ (biomass B III, series 2/1, flue gases FG 3) for a fuel with a low $O / C$ and $H / C$ ratio (high $\mathrm{C}$ content). In each case, a higher fuel-to-oxidiser molar ratio $(f l o)$ corresponds to a higher $L H V$ of the ultimate gas, due to the predominant content of nitrogen in flue gases. 
B I - Fir Mill Waste

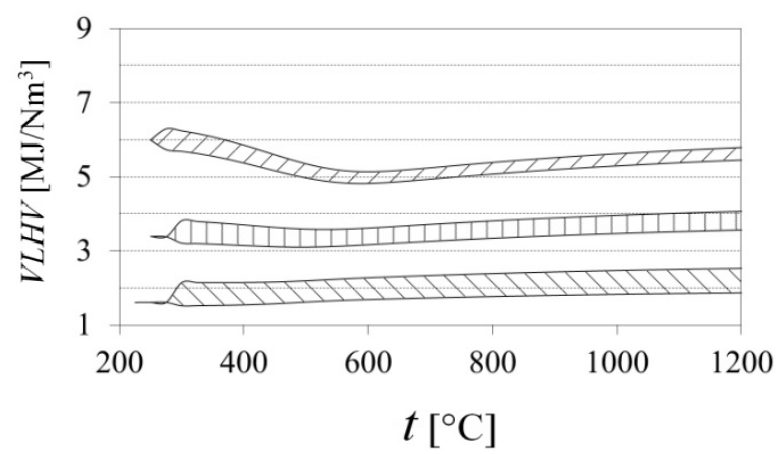

B III - Poplar-Coarse

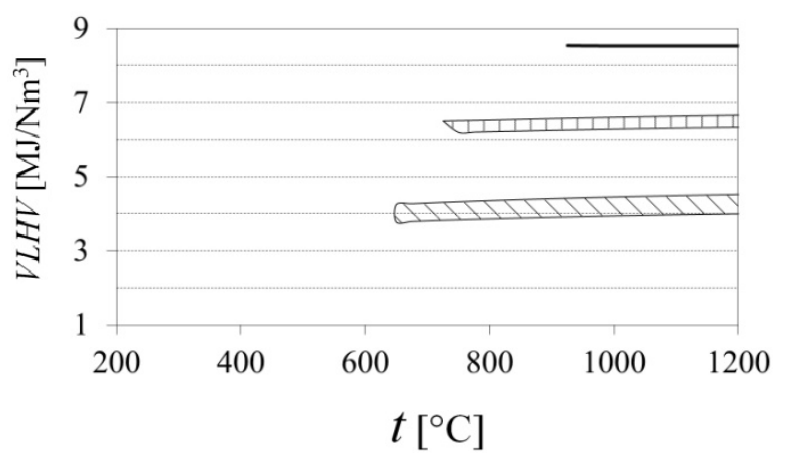

B II - Forest Residuals

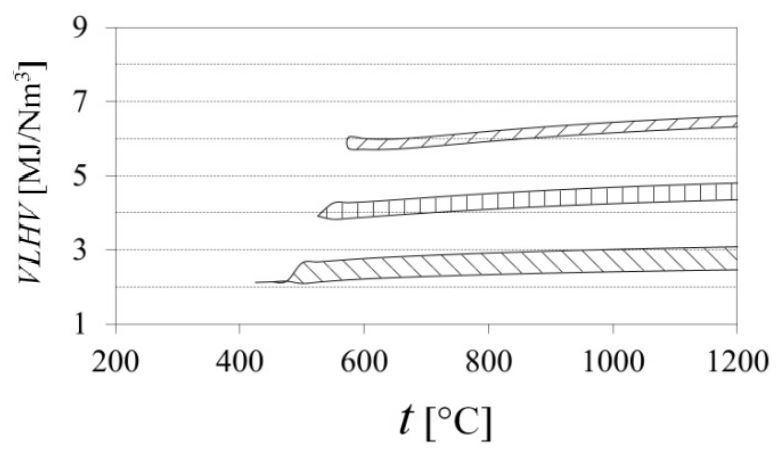

B IV - Olive Pits

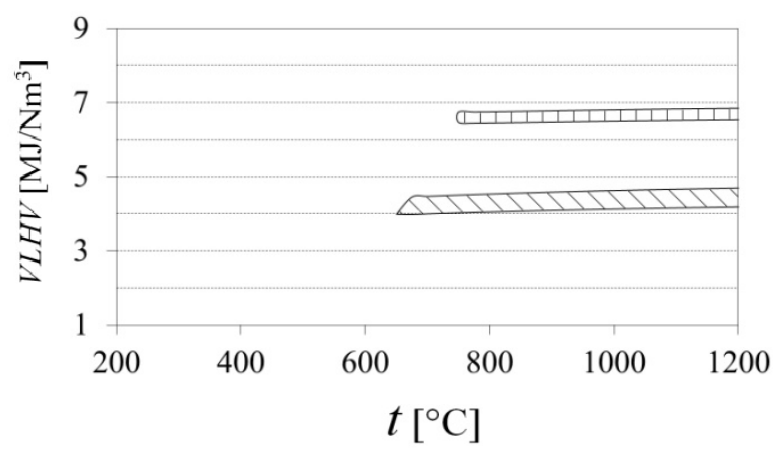

$2 / 1 \quad / / / 1 / 1 \quad|| \mid$ $1 / 2 \quad \backslash \backslash$

Fig. 7. Ranges of the ultimate gas lower calorific value depending on temperature

For fuels B I, B II and B III, the $L H V$ of dry gas reaches the minimum at the following conditions:

- for B I $-350^{\circ} \mathrm{C}$ (series $1 / 2$, flue gases FG 2 only), $500-525^{\circ} \mathrm{C}$ (series $1 / 1$ ) and $600^{\circ} \mathrm{C}$ (series $2 / 1$ ),

- for B II $-625^{\circ} \mathrm{C}$ (series $2 / 1$ ),

- for B III $-1050^{\circ} \mathrm{C}$ (series $2 / 1$, flue gases FG 3 only).

In the other cases, the $L H V$ rises monotonically together with an increase in temperature.

Similar to the charts concerning the contents of the ultimate gas components (Figs. 3-4 and 6), and due to the lack of real results for the assumptions adopted in Figs. 7 and 8, series 2/1 for biomass B IV is not presented, and series $2 / 1$ for biomass B III is marked with a single thick line.

\subsection{Chemical energy conversion rate (CECR)}

The chemical energy conversion rate (Fig. 8) ranges from $67.9 \%$ (biomass B I, series $1 / 2$, flue gases FG 3) for a fuel with a high $O / C$ and $H / C$ ratio to $134.9 \%$ (biomass B III, series $1 / 2$, flue gases FG 4) for a fuel with a low $O / C$ and $H / C$ ratio. Higher $C E C R$ values are achieved for flue gases with a zero content of free oxygen.

The $C E C R$ rises monotonically together with an increase in temperature for all fuel-oxidiser pairs. Depending on the type of fuel and oxidiser, the CECR function has points above which its increment is very small. The parameters of these points indicate the optimization minima of the gasification process temperature, and for the cases under analysis they are as follows: $\mathrm{B} \mathrm{I}-550-650^{\circ} \mathrm{C}$, B II $-600-700^{\circ} \mathrm{C}, \mathrm{B}$ III $-650-925^{\circ} \mathrm{C}, \mathrm{B}$ IV $-650-800^{\circ} \mathrm{C}$. 

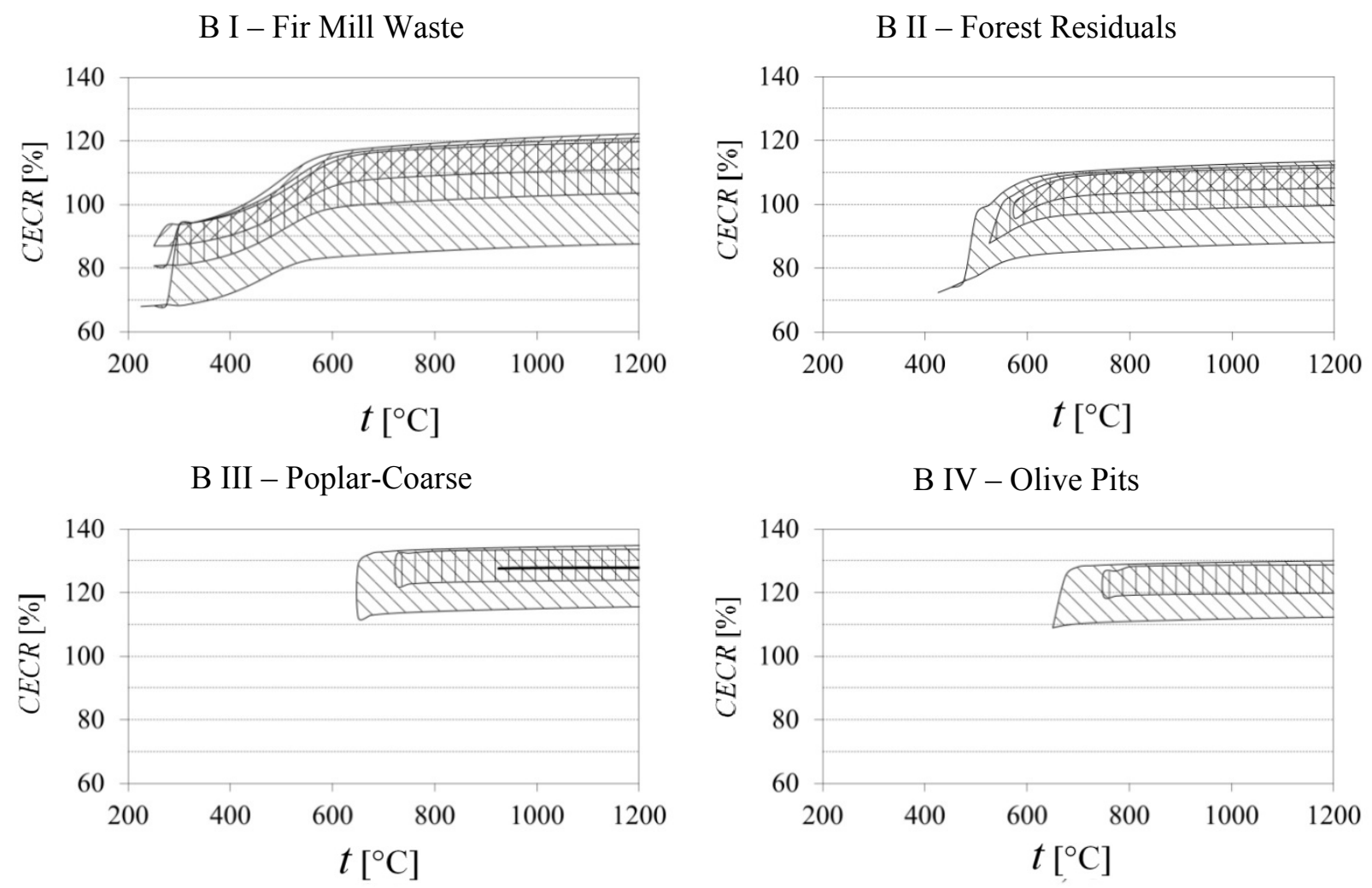

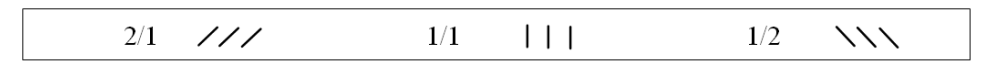

Fig. 8. Ranges of chemical energy conversion rate depending on temperature

In Fig. 8 the wider ranges of the $C E C R$ correspond to a lower flo ratio, which is also the case for the contents of the gas components and the lower calorific value. The overlapping of the ranges allows a conclusion that the composition of the reacting system, appropriately modified by a change in the fuelto-oxidiser ratio and by the change of the oxidiser type, makes it possible to obtain $C E C R$ values which are close to each other. In the case of fuel with a high $O / C$ and $H / C$ ratio (biomass B I), which is gasified in the temperature of $1200^{\circ} \mathrm{C}$ with an oxidiser with a zero content of free oxygen (flue gases FG 2), the difference in the $C E C R$ values between $f / o=1 / 1$ and $f / o=1 / 2$ is $0.2 \%$. Gasification of the same fuel at the same temperature with flue gases with a high content of $\mathrm{O}_{2}$ (flue gases FG 3) could raise that difference to as much as $16.0 \%$. For a fuel with a low $O / C$ and $H / C$ ratio (biomass B IV), the difference - for flue gases with a low and high content of $\mathrm{O}_{2}-$ is: $0.4 \%$ (flue gases FG 2) and $7.6 \%$ (flue gases FG 3), respectively. Consequently, the gas quality, while gasifying biomass with a high $O / C$ and $H / C$ ratio, is much more sensitive to a change in the composition and in the amount of the oxidiser fed into the process than in the case of biomass with low molar ratios of these elements.

\section{INTERPRETATION OF ANALYSIS RESULTS}

Obtaining a high-quality conversion of chemical energy in the gasification process may require a change in the composition or amount of the reactants fed into the process. Although a change in the mass flow of the media is not a problem in this case, a correction in the composition of biomass or flue gases may be troublesome or in fact impossible to carry out.

The most advantageous composition for gasification, considered in terms of the maximum chemical energy conversion rate, is biomass with low values of the $\mathrm{O} / \mathrm{C}$ and $H / C$ ratio and a medium $H / O$ ratio (biomass B III), and flue gases with a zero content of free $\mathrm{O}_{2}$ (flue gases FG 2 and FG 4). The 
composition of flue gases depends on the parameters of the burned fuel and on the boiler structure which forces a particular way of combustion in order to achieve a high efficiency of the facility. For this reason, any interference in the parameters of flue gases is very limited. However, an improvement in the usability of flue gases for the purposes of indirect co-firing is becoming another argument for the reduction in the air excess ratio in boilers.

The unavailability of biomass of varied origin, with a high demand for syngas, may limit the modification of the gasified fuel composition significantly. Different types of dry biomass have a similar chemical composition. The values of the biomass $\mathrm{O} / \mathrm{C}, \mathrm{H} / \mathrm{C}$ and $\mathrm{H} / \mathrm{O}$ ratio are most affected by the moisture content in the fuel. In the reacting system, the ratios could be modified by a change in the amount of $\mathrm{H}_{2} \mathrm{O}$ fed into the system together with gasified fuel, or as an additional gasifying medium.

This in turn points out to a possibility of biomass drying or moisturising in order to improve the chemical energy conversion rate. The inclusion of the drying process in the technology of the system would have to be considered at the design stage, both in terms of satisfying the installation demand for biomass and the possibilities of biomass storage (natural drying), and in terms of including the energy used to dry biomass in dryers in the energy balance of the entire system. It may turn out that the drying of fuel before it is gasified improves the chemical efficiency of gasification, with a simultaneous adverse effect on the total efficiency of the indirect co-firing system. The most economical solution would be to use available waste heat for this purpose.

Also, feeding additional $\mathrm{H}_{2} \mathrm{O}$ into the system, in the form of water or steam, could lead to a situation when the amount of energy used for this purpose is unjustified from the point of view of economy. In the case of fuels with a low $\mathrm{O} / \mathrm{C}$ and $H / C$ ratio, feeding an additional oxidiser in the form of $\mathrm{H}_{2} \mathrm{O}$ or air may be a necessity if the parameters of the reactants and the entire indirect co-firing system make it impossible to run the process above the temperature of total carbon conversion $t_{t c c}$.

From the point of view of gasification optimisation in terms of obtaining the maximum chemical energy conversion rate, it is most beneficial to run the process at the highest possible temperature. The temperature value is limited, however, by the thermal conditions of the process, which are not taken into account in this paper.

\section{CONCLUSIONS}

Complete gasification depends on the temperature of the process and the chemical composition of the reactants. The sensitivity of the composition of the reacting system to the lack of an appropriate amount of oxygen results in a higher temperature of total carbon conversion $t_{t c c}$. The composition and the amounts of the reacting substances fed into the system allow to modify the ultimate gas composition, and consequently - its lower calorific value, the chemical energy conversion rate and temperature $t_{t c c}$. However, the optimisation of the ultimate gas quality is relatively limited; it is possible in the following areas mainly: a change in the fuel-to-oxidiser ratio, a change in the fuel moisture content, or feeding an additional gasifying medium.

The optimum process parameters, determined from the stand point of maximum value of chemical energy conversion rate $(C E C R)$, are:

- possibly high process temperature,

- minimum content of free oxygen in gasifying medium,

- maximum fuel-to-oxidiser ratio, which allows to proceed with the process above temperature $t_{\text {tcc }}$.

The first two parameters clearly indicate the most desirable place for flue gas intake from the boiler to be coupled with gasifier in order to create a combined indirect co-firing unit: boiler furnace. 
The value of $C E C R$ is not unanimously coupled with $O / C, H / C$ and $H / O$ values. Additionally, a lower moisture content of the biomasses under consideration does not always lead to higher $C E C R$. Nevertheless, the majority of cases observed in the study confirm an overall positive influence of lower moisture content and lower $O / C, H / C$ as well as higher $H / O$ values on the $C E C R$ value.

The presented analysis does not provide answers to a range of thermal issues related to flue gas-driven biomass gasification. These issues will be the subject of the next stage of research, conducted by a team of authors and devoted to the development of the indirect co-firing technology.

Summary. With the use of simple indices of the reacting system, a qualitative description of the thermochemical flue-gas driven biomass gasification (a sub-process of indirect co-firing) was made. Under chemical equilibrium conditions, the temperature of total carbon conversion, the composition and the lower calorific value of the ultimate gas, and the chemical energy conversion rate for a maximally varied composition of the process reactants were estimated. Therefore, the obtained results are a point of reference for each type of biomass and flue gases with a chemical composition different from the extreme cases analysed in this paper. The analysis ignores the thermal and kinetic aspects of the gasification process, focusing on the possibility of using various fuel-oxidiser pairs at a constant atmospheric pressure in a possibly wide range of temperatures. The presented equilibrium modelling provides a useful methodological basis for the planning and designing of indirect co-firing systems, in particular - systems of flue gas-driven biomass gasification. On the other hand, the universal character of the described issues makes the conclusions drawn from the analysis be useful for the needs of other processes of chemical processing of fuels.

The work was co-financed by the European Union under the European Social Fund Project "Activation of the academic community as part of the Regional Innovation Strategy" POKL. 08.02.01-24-019/08, and by the National Centre for Research and Development (NCBiR) within the framework of the Technological Initiative II (IniTech), Project No ZPB/57/65392/IT2/10.

\section{SYMBOLS}

$\begin{array}{ll}C E C R & \text { chemical energy conversion rate } \\ C(S) & \text { carbon in solid phase } \\ f l o & \text { fuel - to - oxidiser ratio } \\ G_{i}^{0} & \text { molar free energy of species } i \text { in standard conditions (1 atm, 298 K), kJ/kmol } \\ H / C, H / O, O / C & \text { ratios of the number of moles of elements in the fuel-oxidiser system } \\ L H V_{b, d a f} & \text { lower heating value of biomass (dry, ash-free basis), } \mathrm{kJ} / \mathrm{kg} \\ \dot{m}_{b, d a f} & \text { mass flow rate of biomass (dry, ash-free basis), } \mathrm{kg} / \mathrm{s} \\ n S p & \text { total number of species in the mixture } \\ p & \text { total pressure, Pa } \\ R & \text { universal gas constant }(8.3144 \mathrm{~kJ} /(\mathrm{kmolK})) \\ T & \text { absolute temperature, } \mathrm{K} \\ V L H V_{g, d}, V L H V_{f g, d} & \text { volumetric lower heating value of ultimate gas and of gasifying medium, } \\ \dot{V}_{g, d}, \dot{V}_{f g, d} & \text { respectively (dry basis), } \mathrm{kJ} / \mathrm{Nm}{ }^{3} \\ & \text { volumetric flow of ultimate gas and of gasifying medium, respectively (dry } \\ x_{i} & \text { basis), } \mathrm{Nm}{ }^{3} / \mathrm{s} \\ \sum x_{i} & \text { number of moles of species } i \\ & \text { total number of moles in the mixture }\end{array}$




\section{REFERENCES}

Kalina J., 2011. Modelling of fluidized bed biomass gasification in the quasi-equilibrium regime for preliminary performance studies of energy conversion plants. Chem. Process Eng., 32, 73-89. DOI: 10.2478/v10176-0110007-5.

Kozaczka J., 1994. Gasification processes. Engineering methods of calculations. Wydawnictwa AGH, Cracow (in Polish).

Miles T., Baxter L., Bryers R., Jenkins B., Oden L., 1995. Alkali deposits found in biomass power plants: A preliminary investigation of their extent and nature. National Renewable Energy Laboratory, Golden, CO 1995.

Nadziakiewicz J., Wacławiak K., Stelmach S., 2007. Thermal processes of waste utilization. Wydawnictwo Politechniki Śląskiej, Gliwice (in Polish).

Orłowski P., Dobrzański W., Szwarc E., 1979. Steam boilers. Design and calculations. Wydawnictwa NaukowoTechniczne, Warsaw (in Polish).

Tomeczek J., 1991. Coal gasification. Wydawnictwo Politechniki Śląskiej, Gliwice (in Polish).

Received 19 December 2011

Received in revised form 07 September 2012

Accepted 08 September 2012 